\title{
Disentangling the Contribution of Spatial Reference Frames to Executive Functioning in Healthy and Pathological Aging: An Experimental Study with Virtual Reality
}

\author{
Silvia Serino ${ }^{1,2, *}$, Francesca Morganti ${ }^{3}$, Desirée Colombo ${ }^{4}$, Elisa Pedroli ${ }^{1}$, Pietro Cipresso ${ }^{1,2}$ (1) \\ and Giuseppe Riva ${ }^{1,2}$ \\ 1 Applied Technology for Neuro-Psychology Lab, IRCCS Istituto Auxologico Italiano, Via Magnasco 2, \\ 20149 Milan, Italy; e.pedroli@auxologico.it (E.P.); pietro.cipresso@unicatt.it (P.C.); \\ giuseppe.riva@unicatt.it (G.R.) \\ 2 Department of Psychology, Università Cattolica del Sacro Cuore, Largo Gemelli 1, 20100 Milan, Italy \\ 3 Department of Human and Social Sciences, University of Bergamo, Piazzale S. Agostino 2, 24129 Bergamo, \\ Italy; francesca.morganti@unibg.it \\ 4 Department of Basic Psychology, Clinic and Psychobiology, Universitat Jaume I, Av. Sos Baynat, s/n, \\ 12071 Castellón, Spain; dcolombo@uji.es \\ * Correspondence: s.serino@auxologico.it; Tel.: +39-02-619112726
}

Received: 9 April 2018; Accepted: 28 May 2018; Published: 1 June 2018

\begin{abstract}
A growing body of evidence pointed out that a decline in effectively using spatial reference frames for categorizing information occurs both in normal and pathological aging. Moreover, it is also known that executive deficits primarily characterize the cognitive profile of older individuals. Acknowledging this literature, the current study was aimed to specifically disentangle the contribution of the cognitive abilities related to the use of spatial reference frames to executive functioning in both healthy and pathological aging. 48 healthy elderly individuals and 52 elderly suffering from probable Alzheimer's Disease (AD) took part in the study. We exploited the potentiality of Virtual Reality to specifically measure the abilities in retrieving and syncing between different spatial reference frames, and then we administrated different neuropsychological tests for evaluating executive functions. Our results indicated that allocentric functions contributed significantly to the planning abilities, while syncing abilities influenced the attentional ones. The findings were discussed in terms of previous literature exploring relationships between cognitive deficits in the first phase of AD.
\end{abstract}

Keywords: virtual reality; allocentric abilities; executive functions; syncing abilities; neurodegenerative diseases

\section{Introduction}

To refer to the position of an object in our environment, for example, a bottle on the table, we may simply use the term "left" or "right", adopting therefore our body as reference for its spatial location ("The blue bottle is on my right"). However, if our spatial position changes, the position of the bottle "changes" accordingly. To maintain the spatial position of the bottle in "mind", we have to refer to the relationship existing with other elements in the surroundings, for example the table itself ("The blue bottle is on the table"). These are the two fundamental types of coordinate used to identify locations in space: the egocentric and allocentric spatial reference frames [1,2]. They are also used to refer to spatial entities in language (for a review, see [3]), thus implying that these frames are two crucial modes for organizing information in our entire cognitive system (for their impact on memory, see [4]). Within the 
egocentric reference frame, which is defined by subject-to-object relationships ("The blue bottle is on my right"), information is categorized in relation to the self. Conversely, in an allocentric reference frame, which is formed by object-to-object relations ("The blue bottle in on the table"), information is categorized independently from the self, and it's related to other elements in the environment $[5,6]$. Influential studies in developmental psychology demonstrated that children initially adopt egocentric reference frames to categorize information; only later, they become able to control both frames [7,8].

The process of encoding, storing and retrieval spatial information from environment has been modelled in cognitive neuroscience [6,9]. While moving and interacting with the environment, individuals encode information within an egocentric reference frame within the parietal lobe $[6,9,10]$. Then, egocentric representations are transformed into allocentric representations for long-term storage in medial temporal lobes $[6,9,10]$ thanks to the contribution of the retrosplenial cortex (RCS) [11]. When it is necessary to retrieve an allocentrically-coded representation (for example, I have to retrieve the position of a supermarket previously visited during a tour in a city), the same transformation circuitry should be activated backwards [6,9]. Moreover, the existence of a specific process underlying this egocentric-allocentric transformation, i.e., the Mental Frame Syncing (MFS), has recently been proposed, which is supposed to be crucial to support the recall of spatial information. Indeed, the MFS operates by placing the egocentric heading into the allocentric representation, making easy the translation of this stored abstract allocentric map into an egocentric representation [12-14]. In the previous example, when I have to remember the position of the supermarket, I must also remember my egocentric heading with respect to the supermarket and synchronize these two kinds of information.

Remarkably, the capacity to store allocentric representations seems to be the key spatial ability underlying the decline in navigation abilities observed in both individuals suffering from Alzheimer's Disease (AD) and Mild Cognitive Impairment (MCI) $[15,16]$, especially because the neurodegeneration started in the medial temporal lobe and related areas [17-21]. However, it is also known that a decline in spatial abilities occurs also in normal aging, involving both spatial memory [22-24] and spatial navigation [16]. More specifically, an increasing number of studies emphasized a decline of allocentric abilities after the 60 years of age, which was related with the physiological deterioration of hippocampal areas [25-28].

However, a growing body of evidence also suggested an association between the ability in using spatial reference frames for memory and navigation, and other cognitive abilities, such as executive functions [29-31]. Indeed, it has been suggested that the general age-related cognitive decline is particularly linked to the weakening of executive functioning [32], which comprises a set of different cognitive abilities necessary to plan, organize, execute and monitor actions. This age-related decline in executive functions can negatively affect performance in spatial navigation [33], since it implies the correct organization of actions within the environment, the monitoring of their outcome, and the search for another strategy if it fails. In this vein, an interesting study [30] employing a Virtual Reality (VR)-based navigation task indicated for older adults a reduced activation in brain areas typically involved in allocentric navigation (i.e., the hippocampus, the parahippocampal gyrus, the retrosplenial cortex and the parietal lobes), and a greater frontal lobe activation (typically associated with the executive functioning). In the same direction, more recently, Laczò and co-workers [29] demonstrated the presence of an association between allocentric navigation and executive functions in a sample of individuals with amnestic MCI.

Understanding the association between deficits, spatial reference frames, and executive impairments in healthy and pathological aging represents an opportunity to highlight which cognitive markers primarily characterize neurodegenerative diseases.

In this perspective, VR offers tremendous advantages for specifically investigating allocentric and egocentric abilities [15,34]. Besides the opportunity for an ecological, controlled and secure testing, within virtual environments, it is possible to set-up a "reorientation task" by systematically varying the starting point of the retrieval phase with respect to the encoding phase $[35,36]$. This strategy (i.e., the virtual disorientation) forces participants to refer to their stored allocentric map and 
synchronize it with new egocentric input (i.e., the MFS ability) to orient in the environment [37-39]. In a recent study from our group, we exploited the potential of VR to study the presence of allocentric and syncing deficits in a sample of patients with $\mathrm{AD}$ and amnestic $\mathrm{MCI}$. We found that the cognitive profile of amnesic MCI patients was marked by an allocentric impairments. Instead, a more subtle deficit in the synchronization ability was found in patients suffering from AD.

To further investigate the association between the ability to use spatial reference frames and executive functions, in the current study, we recruited 48 healthy elderly individuals and 52 elderly individuals suffering from probable AD. Accordingly, we employed a VR-based task (adopted in a previous study [39]) to measure allocentric and syncing abilities, and then, we administrated different neuropsychological tests for evaluating executive functions. The aim was to specifically disentangle the contribution of the cognitive abilities related to the use of spatial references frames to executive functioning in both healthy and pathological aging.

\section{Materials and Methods}

\subsection{Participants}

100 elderly subjects participated in the study: 48 healthy elderly individuals and 52 elderly individuals suffering from probable AD. The healthy elderly individuals were recruited from a panel of volunteers. Inclusion criteria were: (1) age older than 65 years old; (2) no history or presence of psychiatric or neurological disorders (evaluated with a brief interview); (3) normal or corrected-to-normal vision; (4) scores on Mini-Mental State Examination-MMSE [40] over than 27. $\mathrm{AD}$ patients were recruited from different social senior centres located in Lombardy (Italy). Inclusion criteria for individuals with AD were: (1) age older than 65 years old; (2) diagnosis of AD according to NINCDS-ARDRA criteria made by neurologist/geriatric staff of social senior centre [41]; (3) no history or presence of psychiatric or neurological disorders other than AD; (4) normal or corrected-to-normal vision; and (5) scores on Milan Overall Dementia Scale [42] under 85.5 (i.e., clinical cut-off for probable dementia due to Alzheimer's Disease).

AD patients had a mean score at Mini-Mental State Examination-MMSE [40] of 21.54 (SD = 2.71), while the healthy elderly individuals had a mean score of $28.86(\mathrm{SD}=1.15)$. The AD patients were composed of 39 women and 13 men, while the CG included 33 women and 15 men [ $\left(\chi^{2}=0.484(1)\right.$; $p=0.487)]$. The mean age for the $\mathrm{AD}$ group was $84.40(\mathrm{SD}=4.67)$, with a mean years of education of 6.36 ( $\mathrm{SD}=3.18$ ), while the mean age for the $\mathrm{CG}$ was $82.54(\mathrm{SD}=7.27)$, with a mean years of education of $7.15(\mathrm{SD}=3.00)$. There were no significant differences between the two groups concerning age $[t(98)=-1.536 ; p=0.128)]$ or education $[t(98)=1.262 ; p=0.210)]$. All participants wrote a consent to be included in the study, which was approved by the Ethical Committee of Università Cattolica del Sacro Cuore di Milano.

\subsection{Executive Functions Assessment}

To obtain a thorough picture of the executive functioning of our sample, the following tests were administered to all participants: the Tower of London [43] to specifically evaluate planning abilities and The Trail Making Test, in its two versions, A and B [44]. Specifically, TMT-A evaluates attentional abilities, whereas TMT-B measures cognitive flexibility as components of executive functioning.

\subsection{Virtual Reality Procedure}

A Virtual Reality (VR) - based procedure was used to evaluate the ability to retrieve and sync between different spatial reference frames [39]. First of all, participants were presented to VR technology to familiarize with it (i.e., approximately two-five minutes). In this phase, they entered a stimulus-free virtual room, and they were instructed on how to navigate inside it. Then, the VR-based procedure started, which consisted of two phases: a encoding and a retrieval phase. They entered in a virtual room which included two objects (i.e., a plant and a stone) and a blue arrow drawn on the floor, 
which pointed to the North (encoding phase) and signaled to participants the center of the testing room (see Figure 1).

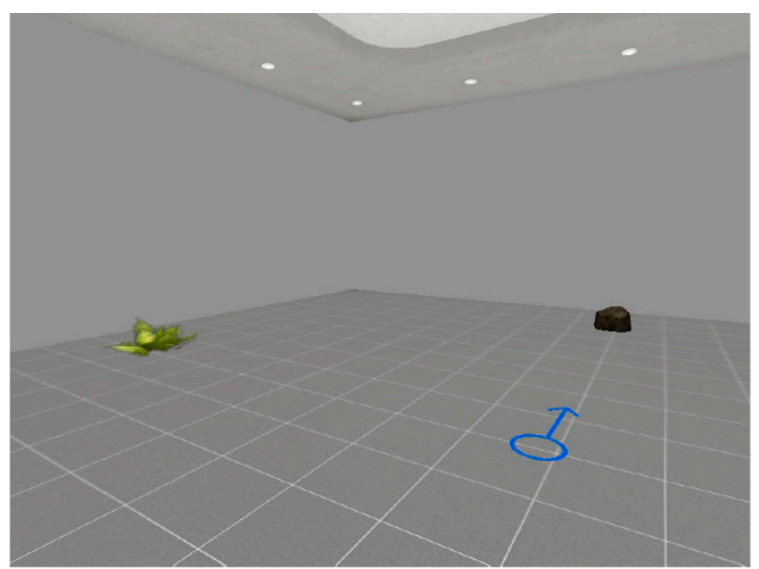

Figure 1. The VR-based procedure (encoding phase). In this phase, participants entered in the virtual room and they were asked to memorize the position of the plant.

Participants were invited to memorize the position of the plant, which was posited at the western part of the virtual room. The stone was located on the north side of the environment. Successfully, they were asked to retrieve its position in two different retrieval tasks (retrieval phase). The first task involved an aerial map of the room (i.e., a task that measures the ability to store an allocentric reference frame-Allocentric Abilities); the second task will involve entering the virtual room, but this time from another starting point (i.e., a task that measures the Mental Frame Syncing abilities [12-14]—Syncing Abilities). The accuracy of spatial location was the dependent variable in both retrieval tasks: $0=$ poor answer (for example, choosing the same side of the retrieval point, i.e., the North); $1=$ correct answer. This VR-based procedure was developed using NeuroVirtual 3D, a recent extension of the software NeuroVR (version 2.0, Milan, Italy) [45,46]. NeuroVirtual 3D software (http:/ / www.neurovirtual.eu) provides a free virtual-reality platform for easily customizing virtual environments from a predefined library of existing ones (park, supermarket, station, etc.) that can be used for neuroscience research. It is composed of two modules: an Editor, for the customization of virtual scenes, and a Player, for the visualization of customized scenes in immersive (with the Vuzix Head Mounted Display) and not-immersive modality.

\subsection{Procedure}

Participants gave their informed consent to be included in the study. Then, they underwent the neuropsychological assessment to obtain a complete evaluation of their executive functioning. After the neuropsychological evaluation, participants were asked to perform the VR-based task. Participants were invited to sit comfortably in a quiet room in front of a portable computer (ACER ASPIRE with CPU Intel ${ }^{\circledR}$ Core ${ }^{\mathrm{TM}} \mathrm{i} 5$ and graphic processor Nvidia GeForce GT $540 \mathrm{M}, 1024 \times 768$ resolution). A gamepad was used to explore and interact with the virtual room (Logitech Rumble F510). The training phase was delivered to allow participants interacting autonomously with VR (approximately two-five minutes). Then, the VR-based task started; its scope was to measure in two different retrieval tasks (i.e., "Allocentric Abilities" and "Syncing Abilities") the ability to store and sync between different spatial reference frame.

\subsection{Data Analyses}

Preliminary, group comparisons among the different neuropsychological tests were carried by univariate analysis of covariance (ANCOVA), using age and education as covariates. As concerns 
behavioral indices from the VR-based tasks, group comparisons were examined by $\chi^{2}$ tests. Then, generalized linear models [47] were applied to investigate the contribution of the abilities in retrieving and syncing between spatial references frames ("Allocentric Abilities" or "Syncing Abilities") to the executive functioning. These analyses included scores on MMSE as covariate predictors. Statistical analyses were performed in SPSS Statistics 21 (IBM, Armonk, NY, USA).

\section{Results}

\section{Group Differences Executive Functions and Spatial Reference Frames}

Table 1 offers a picture of all data obtained from the neuropsychological assessment divided between the two groups and the statistical comparisons. When controlling for age and education, comparison of scores between groups using ANCOVA revealed significant differences as concerns all the tests considered (all $p<0.05$ ). Patients suffering from AD performed significantly worse than healthy elderly individuals in all traditional tests evaluating executive functions (see Table 1). Results obtained from the $\chi^{2}$ tests indicated a significant difference among the AD and healthy elderly also regarding indices from the VR-based tasks (see Table 1). In particular, it emerged a significant difference among the two groups in the Allocentric Abilities, while just a trend to significance was observed in the Syncing Abilities $(p=0.06)$.

Table 1. Scores obtained from executive functions and spatial references for healthy elderly individuals and patients suffering from Alzheimer's Disease.

\begin{tabular}{cccccc}
\hline & Healthy Elderly Group & AD Group & F & $p^{*}{\text { Partial } \eta p^{2}}^{2}$ \\
\hline Tower of London (ToL) $^{1}$ & $23.13^{2}(7.76)$ & $18.38^{2}(8.37)$ & 10.678 & 0.002 & 0.100 \\
Trail Making Test-TMT-A ${ }^{1}$ & $101.64^{2}(70.23)$ & $236.94^{2}(182.31)$ & 17.865 & $<0.001$ \\
Trail Making Test-TMT-B ${ }^{1}$ & $261.01^{2}(195.19)$ & $530.27^{2}(272.55)$ & 11.704 & 0.001 & 0.164 \\
Allocentric Abilities & $89 . \%^{3}$ & $71 . \%^{3}$ & $5.298^{4}$ & 0.021 & $0.23^{5}$ \\
Syncing Abilities & $35 . \%^{3}$ & $19.2 \%{ }^{3}$ & $3.318^{4}$ & 0.060 & $0.181^{5}$ \\
\hline
\end{tabular}

${ }^{1}$ For Tower of London (TOL), higher scores meant better performance; for Trial Making Test (TMT-A and TMT-B), higher scores meant worst performance. ${ }^{2}$ Data are shown as means and standard deviations (SD). ${ }^{3}$ Percentage of correct response; ${ }^{4} \chi^{2}$ test; ${ }^{5}$ Effect size for $\chi^{2}$ test: $\varphi=\sqrt{\frac{\chi^{2}}{n}}$.

In Tables 2 and 3, we reported results obtained from the generalized linear models to investigate the contribution of the Allocentric and Syncing Abilities ("Factor") to executive functions ("Response"). In all models, scores on MMSE were inserted as covariates predictor.

Table 2. Association between allocentric abilities and executive functions.

\begin{tabular}{ccccc}
\hline & B & Standard Error & $\chi^{2}$ & $p$ \\
\hline Tower of London & & & & \\
Allocentric Abilities & 21.507 & 109.160 & 3.882 & 0.049 \\
MMSE & 0.942 & 0.2276 & 17.127 & $<0.001$ \\
Allocentric Abilities * MMSE & -0.788 & 0.4576 & 0.2966 & 0.085 \\
\hline Trail Making Test-TMT-A & & & & \\
Allocentric Abilities & 10.079 & $1,852.216$ & 0.003 & 0.957 \\
MMSE & -16.716 & 3.919 & 18.240 & $<0.001$ \\
Allocentric Abilities * MMSE & 1.338 & 77.624 & 0.030 & 0.863 \\
\hline Trail Making Test-TMT-B & & & \\
Allocentric Abilities & 419.823 & $4,405.849$ & 0.908 & 0.341 \\
MMSE & -22.863 & 95.138 & 5.775 & 0.016 \\
Allocentric Abilities * MMSE & -11.997 & 184.083 & 0.425 & 0.515 \\
\hline
\end{tabular}

${ }^{*}$ Interaction between variables. 
Table 3. Association between syncing abilities and executive functions.

\begin{tabular}{ccccc}
\hline & B & Standard Error & $\chi^{2}$ & $p$ \\
\hline Tower of London & & & & \\
Syncing Abilities & 77.392 & 107.488 & 0.518 & 0.47 \\
MMSE & 0.798 & 0.3455 & 5.341 & 0.021 \\
Syncing Abilities * MMSE & -0.246 & 0.4145 & 0.352 & 0.553 \\
\hline Trail MakingTest-TMT-A & & & \\
Syncing Abilities & -378.637 & $1,845.662$ & -16.894 & 0.040 \\
MMSE & -27.474 & 60.083 & 20.909 & $<0.001$ \\
Syncing Abilities * MMSE & 13.354 & 71.118 & 3.526 & 0.060 \\
\hline Trail Making Test-TMT-B & & & & \\
Syncing Abilities & -572.617 & $4,549.136$ & 1.584 & 0.208 \\
MMSE & -45.045 & 146.802 & 9.415 & 0.002 \\
Syncing Abilities * MMSE & 20.693 & 174.524 & 1.406 & 0.236 \\
\hline
\end{tabular}

${ }^{*}$ Interaction between variables.

On one hand, statistical analyses indicated a significant effect of the Allocentric Abilities on the performance in the Tower of London ( $p=0.049$, see Table 2$)$. On the other hand, the Syncing Abilities on the first task of the Trail-Making Test, the TMT-A, had significant impact. In all models, the scores on MMSE significantly influenced the performance in tasks evaluating executive functions. No significant interaction effect was observed between abilities in using spatial reference frames (neither in "Allocentric Abilities" or "Syncing Abilities") and scores on MMSE on executive functions. A trend to significance can be observed concerning the interaction "Syncing Abilities $\times$ MMSE" on TMT-A $(p=0.060)$.

\section{Discussion}

A growing body of evidence suggested that a decline in effectively using spatial reference frames for categorizing information occurs both in normal and pathological aging [15,48]. On the other hand, evidence indicated that: (1) an early decline in allocentric abilities is one of the first hallmarks of Alzheimer's Disease (AD) [15]; (2) executive deficits primarily characterize the cognitive profile of older individuals (the so-called "frontal lobe hypothesis" $[49,50]$ ), because of the anatomical and functional deterioration occurring in frontal lobes. Literature underlined an association between the ability to use spatial reference frames and executive functions [29-31].

In this direction, the objective of the current study was to understand the contribution of abilities in using spatial reference frames in executive functioning. Indeed, findings obtained up to now raise the question: to what extent can spatial reference frames impairments have an influence on executive functions in both healthy and pathological aging?

First of all, our results confirmed but also extended previous knowledge about cognitive deficits early manifested in AD [15,16,51-57]. Our outcomes pointed out the presence of executive deficits among individuals with AD. In particular, they manifested difficulties in different aspects of executive functioning, from planning (Tower of London), to attentional and multitasking abilities (Trail Making Test A and B).

In literature, there were contrasting results about the executive impairments in the first phase of $\mathrm{AD}[54,55]$. For instance, Collette and co-workers highlighted that patients with AD reported executive impairments related to controlled attention and working memory. This implies the involvement of parietal-temporal cortex regions that are importantly affected in AD. In fact, the anatomical correlates of executive impairments in the disease are still under debate, but an early disconnection in the parietal-temporal network has been proposed [58]. 
Understanding which are the cognitive deficits early affected in AD is of primary importance; our results highlighting the presence of large executive impairments in the first stage of this disease could be of value for the early detection of subtle cognitive weaknesses [59].

In the same perspective, our findings highlighted the presence of spatial reference frames impairments among individuals with $\mathrm{AD}$, consistent with previous studies in this field [15]. The cognitive profile of $\mathrm{AD}$ appears to be characterized by an early decline in allocentric retrieval, combined with an early decline in other subtle neurocognitive mechanisms useful to support the allocentric-to-egocentric switching, i.e., the Mental Frame Syncing $[12,13,60]$, linked to brain changes occurring in hippocampal regions [60-63] and in retrosplenial cortex [64-66].

Beyond the important possibility of early detection of cognitive impairments among individuals in the first stage of $\mathrm{AD}$, another crucial research area that deserves attention is that related to the relationship between these early cognitive impairments manifested by patients.

In particular, as concerns the contribution of abilities in using spatial reference frames to executive functioning, an interesting pattern emerged from our results. Indeed, our findings indicated that allocentric functions contributed significantly to planning abilities, while syncing abilities influenced significantly attentional ones. It is possible to explain these results considering that allocentric elaborations require an active cognitive elaboration of the external environment, relying on the continuous construction of relations between spatial representations and landmarks, while the ability in syncing between different spatial reference frames recruits more attentional resources (see also [67-70]).

The efforts in understanding the relationship between cognitive weaknesses in AD population may also open interesting rehabilitation possibilities. For example, Serino and colleagues found that a VR-based training specifically built for the empowerment of the "Mental Frame Syncing" in a sample of patients with AD led also to an improvement in some tests tapping executive functioning (i.e., Verbal Fluency Test, Verbal Categorical Test, and FAB) [37]. Influencing higher-order cognitive abilities, such as the executive functions, the spatial reference frames appear to dramatically impact the way individuals categorize information.

Eventually, from our study, the role of VR emerged as an advanced neuroscientific tool for assessing in ecological way complex spatial functions [71,72], also with pathological populations (for an example see [73]). Future studies should further exploit the potential of VR both to set-up innovative instruments able to detect early deficits or to support training in AD population, adopting also more immersive solutions [74,75], and to connect spatial reference frames to internal bodily states [76] within the "embodied medicine" perspective [77].

However, there are some limitations in our study that we should consider. The sample we recruited for this study was rather small, although well-matched for the main sociodemographic characteristics. Second, it would have been crucial to include in the study a group of patients suffering from MCI, mainly to evaluate the association between abilities in using spatial reference frames and executive functioning also in this intermediate stage of pathological aging to deeply investigate the role of executive functions and spatial reference frames as diagnostic markers of AD. Moreover, we could not deeply investigate the neural mechanisms involved in executive functions or the association with other cognitive abilities, such as the episodic memory [53], which is the another crucial cognitive marker of AD.

Author Contributions: S.S., F.M. and D.C. conceived and designed the experiments; S.S. performed the experiments; S.S., P.C. and E.P. analyzed the data; S.S. wrote the first draft of the paper. All authors were involved to critical discussion and approved the manuscript.

Funding: This work was partially supported by the Italian funded project "High-end and Low-End Virtual Reality Systems for the Rehabilitation of Frailty in the Elderly" (PE-2013-02355948).

Conflicts of Interest: The authors declare no conflict of interest. 


\section{References}

1. Klatzky, R.L. Allocentric and egocentric spatial representations: Definitions, distinctions, and interconnections. In Spatial Cognition. An Interdisciplinary Approach to Representing and Processing Spatial Knowledge; Freksa, C., Habel, C., Wender, K.F., Eds.; Springer: Berlin/Heidelberg, Germany, 1998; pp. 1-17.

2. Paillard, J. Brain and Space; OxfordScience Publications: Oxford, UK, 1991.

3. Gallistel, C.R. Language and spatial frames of reference in mind and brain. Trends Cogn. Sci. 2002, 6, 321-322. [CrossRef]

4. Shelton, A.L.; McNamara, T.P. Systems of spatial reference in human memory. Cogn. Psychol. 2001, 43, 274-310. [CrossRef] [PubMed]

5. Galati, G.; Pelle, G.; Berthoz, A.; Committeri, G. Multiple reference frames used by the human brain for spatial perception and memory. Exp. Brain Res. 2010, 206, 109-120. [CrossRef] [PubMed]

6. Byrne, P.; Becker, S.; Burgess, N. Remembering the past and imagining the future: A neural model of spatial memory and imagery. Psychol. Rev. 2007, 114, 340. [CrossRef] [PubMed]

7. Acredolo, L.P. Developmental changes in the ability to coordinate perspectives of a large-scale space. Dev. Psychol. 1977, 13, 1. [CrossRef]

8. Piaget, J. He Child's Conception of the World. London: Kegan Paul Trench Trubner; Original Work Published in 1926; La Concorde: Lausanne, Switzerland, 1929.

9. Burgess, N. Spatial memory: How egocentric and allocentric combine. Trends Cogn. Sci. 2006, 10, 551-557. [CrossRef] [PubMed]

10. Zaehle, T.; Jordan, K.; Wüstenberg, T.; Baudewig, J.; Dechent, P.; Mast, F.W. The neural basis of the egocentric and allocentric spatial frame of reference. Brain Res. 2007, 1137, 92-103. [CrossRef] [PubMed]

11. Marchette, S.A.; Vass, L.K.; Ryan, J.; Epstein, R.A. Anchoring the neural compass: Coding of local spatial reference frames in human medial parietal lobe. Nat. Neurosci. 2014, 17, 1598-1606. [CrossRef] [PubMed]

12. Serino, S.; Riva, G. Getting lost in Alzheimer's Disease: A break in the mental frame syncing. Med. Hypotheses 2013, 80, 416-421. [CrossRef] [PubMed]

13. Serino, S.; Riva, G. What is the role of spatial processing in the decline of episodic memory in Alzheimer's Disease? The "mental frame syncing" hypothesis. Front. Aging Neurosci. 2014, 6, 33. [CrossRef] [PubMed]

14. Serino, S.; Riva, G. The proactive self in space: How egocentric and allocentric spatial impairments contribute to anosognosia in Alzheimer's Disease. J. Alzheimers Dis. 2016, 55, 881-892. [CrossRef] [PubMed]

15. Serino, S.; Cipresso, P.; Morganti, F.; Riva, G. The role of egocentric and allocentric abilities in Alzheimer's Disease: A systematic review. Ageing Res. Rev. 2014, 16, 32-44. [CrossRef] [PubMed]

16. Lithfous, S.; Dufour, A.; Després, O. Spatial navigation in normal aging and the prodromal stage of Alzheimer's Disease: Insights from imaging and behavioral studies. Ageing Res. Rev. 2013, 12, $201-213$. [CrossRef] [PubMed]

17. Braak, H.; Braak, E. Neuropathological stageing of alzheimer-related changes. Acta Neuropathol. 1991, 82, 239-259. [CrossRef] [PubMed]

18. Braak, H.; Braak, E. Evolution of the neuropathology of Alzheimer's Disease. Acta Neurol. Scand. 1996, 94, 3-12. [CrossRef]

19. Alafuzoff, I.; Arzberger, T.; Al-Sarraj, S.; Bodi, I.; Bogdanovic, N.; Braak, H.; Bugiani, O.; DelTredici, K.; Ferrer, I.; Gelpi, E. Staging of neurofibrillary pathology in Alzheimer's Disease: A study of the brainnet europe consortium. Brain Pathol. 2008, 18, 484-496. [CrossRef] [PubMed]

20. Dickson, D.W. The pathogenesis of senile plaques. J. Neuropathol. Exp. Neurol. 1997, 56, 321-339. [CrossRef] [PubMed]

21. Thal, D.R.; Rüb, U.; Schultz, C.; Sassin, I.; Ghebremedhin, E.; Del Tredici, K.; Braak, E.; Braak, H. Sequence of a $\beta$ protein deposition in the human medial temporal lobe. J. Neuropathol. Exp. Neurol. 2000, 59, $733-748$. [CrossRef] [PubMed]

22. Wolbers, T.; Dudchenko, P.A.; Wood, E.R. Spatial memory-a unique window into healthy and pathological aging. Front. Aging Neurosci. 2014, 6, 35. [CrossRef] [PubMed]

23. Iachini, I.; Iavarone, A.; Senese, V.P.; Ruotolo, F.; Ruggiero, G. Visuospatial memory in healthy elderly, ad and mci: A review. Curr. Aging Sci. 2009, 2, 43-59. [CrossRef] [PubMed] 
24. Nemmi, F.; Boccia, M.; Guariglia, C. Does aging affect the formation of new topographical memories? Evidence from an extensive spatial training. Neuropsychol. Dev. Cogn. B Aging Neuropsychol. Cogn. 2017, 24, 29-44. [CrossRef] [PubMed]

25. Gazova, I.; Laczó, J.; Rubinova, E.; Mokrisova, I.; Hyncicova, E.; Andel, R.; Vyhnalek, M.; Sheardova, K.; Coulson, E.J.; Hort, J. Spatial navigation in young versus older adults. Front. Aging Neurosci. 2013, 5, 94. [CrossRef] [PubMed]

26. Ruggiero, G.; D'Errico, O.; Iachini, T. Development of egocentric and allocentric spatial representations from childhood to elderly age. Psychol. Res. 2016, 80, 259-272. [CrossRef] [PubMed]

27. Montefinese, M.; Sulpizio, V.; Galati, G.; Committeri, G. Age-related effects on spatial memory across viewpoint changes relative to different reference frames. Psychol. Res. 2015, 79, 687-697. [CrossRef] [PubMed]

28. Wiener, J.M.; Kmecova, H.; de Condappa, O. Route repetition and route retracing: Effects of cognitive aging. Front. Aging Neurosci. 2012, 4, 7. [CrossRef] [PubMed]

29. Laczó, J.; Andel, R.; Nedelska, Z.; Vyhnalek, M.; Vlcek, K.; Crutch, S.; Harrison, J.; Hort, J. Exploring the contribution of spatial navigation to cognitive functioning in older adults. Neurobiol. Aging 2017, 51, 67-70. [CrossRef] [PubMed]

30. Moffat, S.D.; Elkins, W.; Resnick, S.M. Age differences in the neural systems supporting human allocentric spatial navigation. Neurobiol. Aging 2006, 27, 965-972. [CrossRef] [PubMed]

31. Moffat, S.D.; Kennedy, K.M.; Rodrigue, K.M.; Raz, N. Extrahippocampal contributions to age differences in human spatial navigation. Cereb. Cortex 2006, 17, 1274-1282. [CrossRef] [PubMed]

32. Salthouse, T.A. The processing-speed theory of adult age differences in cognition. Psychol. Rev. 1996, $103,403$. [CrossRef] [PubMed]

33. Finkel, D.; Reynolds, C.A.; McArdle, J.J.; Pedersen, N.L. Age changes in processing speed as a leading indicator of cognitive aging. Psychol. Aging 2007, 22, 558. [CrossRef] [PubMed]

34. Bohil, C.J.; Alicea, B.; Biocca, F.A. Virtual reality in neuroscience research and therapy. Nat. Rev. Neurosci. 2011, 12, 752. [CrossRef] [PubMed]

35. Bosco, A.; Picucci, L.; Caffo, A.O.; Lancioni, G.E.; Gyselinck, V. Assessing human reorientation ability inside virtual reality environments: The effects of retention interval and landmark characteristics. Cogn. Process. 2008, 9, 299-309. [CrossRef] [PubMed]

36. Caffò, A.O.; De Caro, M.F.; Picucci, L.; Notarnicola, A.; Settanni, A.; Livrea, P.; Lancioni, G.E.; Bosco, A. Reorientation deficits are associated with amnestic mild cognitive impairment. Am. J. Alzheimers Dis. Other Dement. 2012, 27, 321-330. [CrossRef] [PubMed]

37. Serino, S.; Pedroli, E.; Tuena, C.; De Leo, G.; Stramba-Badiale, M.; Goulene, K.; Mariotti, N.G.; Riva, G. A novel virtual reality-based training protocol for the enhancement of the "mental frame syncing" in individuals with Alzheimer's Disease: A development-of-concept trial. Front. Aging Neurosci. 2017, 9, 240. [CrossRef] [PubMed]

38. Serino, S.; Riva, G. How different spatial representations interact in virtual environments: The role of mental frame syncing. Cogn. Process. 2015, 16, 191-201. [CrossRef] [PubMed]

39. Serino, S.; Morganti, F.; Di Stefano, F.; Riva, G. Detecting early egocentric and allocentric impairments deficits in Alzheimer's Disease: An experimental study with virtual reality. Front. Aging Neurosci. 2015, 7, 88. [CrossRef] [PubMed]

40. Folstein, M.F.; Robins, L.N.; Helzer, J.E. The mini-mental state examination. Arch. Gen. Psychiatry 1983, 40, 812. [CrossRef] [PubMed]

41. McKhann, G.; Drachman, D.; Folstein, M.; Katzman, R.; Price, D.; Stadlan, E.M. Clinical diagnosis of Alzheimer's Disease report of the nincds-adrda work group* under the auspices of department of health and human services task force on Alzheimer's Disease. Neurology 1984, 34, 939. [CrossRef] [PubMed]

42. Brazzelli, M.; Capitani, E.; Della Sala, S.; Spinnler, H.; Zuffi, M. A neuropsychological instrument adding to the description of patients with suspected cortical dementia: The milan overall dementia assessment. J. Neurol. Neurosurg. Psychiatry 1994, 57, 1510-1517. [CrossRef] [PubMed]

43. Shallice, T. Specific impairments of planning. Philos. Trans. R. Soc. Lond. B Biol. Sci. 1982, 298, 199-209. [CrossRef] [PubMed]

44. Giovagnoli, A.R.; Del Pesce, M.; Mascheroni, S.; Simoncelli, M.; Laiacona, M.; Capitani, E. Trail making test: Normative values from 287 normal adult controls. Ital. J. Neurol. Sci. 1996, 17, 305-309. [CrossRef] [PubMed] 
45. Cipresso, P.; Serino, S.; Pallavicini, P.; Gaggioli, A.; Riva, G. Neurovirtual 3d: A multiplatform 3d simulation system for application in psychology and neuro-rehabilitation. In Virtual, Augmented Reality and Serious Games for Healthcare 1; Springer: Berlin, Germany, 2014; pp. 275-286.

46. Riva, G.; Gaggioli, A.; Grassi, A.; Raspelli, S.; Cipresso, P.; Pallavicini, F.; Vigna, C.; Gagliati, A.; Gasco, S.; Donvito, G. NeuroVR 2-A free virtual reality platform for the assessment and treatment in behavioral health care. In Studies in Health Technology and Informatics; IOS Press: Amsterdam, The Netherlands, 2011; Volume 163, pp. 493-495.

47. Ahrmeir, L.; Tutz, G. Multivariate Statistical Modelling Based on Generalized Linear Models; Springer Science \& Business Media: Berlin, Germany, 2013.

48. Colombo, D.; Serino, S.; Tuena, C.; Pedroli, E.; Dakanalis, A.; Cipresso, P.; Riva, G. Egocentric and allocentric spatial reference frames in aging: A systematic review. Neurosci. Biobehav. Rev. 2017, 80, 605-621. [CrossRef] [PubMed]

49. West, R. In defense of the frontal lobe hypothesis of cognitive aging. J. Int. Neuropsychol. Soc. 2000, 6, 727-729. [CrossRef] [PubMed]

50. West, R.L. An application of prefrontal cortex function theory to cognitive aging. Psychol. Bull. 1996, 120, 272. [CrossRef] [PubMed]

51. Allison, S.L.; Fagan, A.M.; Morris, J.C.; Head, D. Spatial navigation in preclinical Alzheimer's Disease. J. Alzheimers Dis. 2016, 1-14. [CrossRef] [PubMed]

52. Gazova, I.; Vlcek, K.; Laczo, J.; Nedelska, Z.; Hyncicova, E.; Mokrisova, I.; Sheardova, K.; Hort, J. Spatial navigation-A unique window into physiological and pathological aging. Front. Aging Neurosci. 2012, 4, 16. [CrossRef] [PubMed]

53. Boccia, M.; Silveri, M.C.; Sabatini, U.; Guariglia, C.; Nemmi, F. Neural underpinnings of the decline of topographical memory in mild cognitive impairment. Am. J. Alzheimers Dis. Other Dement. 2016, 31, 618-630. [CrossRef] [PubMed]

54. Baudic, S.; Dalla Barba, G.; Thibaudet, M.C.; Smagghe, A.; Remy, P.; Traykov, L. Executive function deficits in early Alzheimer's Disease and their relations with episodic memory. Arch. Clin. Neuropsychol. 2006, 21, 15-21. [CrossRef] [PubMed]

55. Binetti, G.; Magni, E.; Padovani, A.; Cappa, S.F.; Bianchetti, A.; Trabucchi, M. Executive dysfunction in early Alzheimer's Disease. J. Neurol. Neurosurg. Psychiatry 1996, 60, 91-93. [CrossRef] [PubMed]

56. Collette, F.; Van der Linden, M.; Salmon, E. Executive dysfunction in Alzheimer's Disease. Cortex 1999, 35, 57-72. [CrossRef]

57. Lafleche, G.; Albert, M.S. Executive function deficits in mild Alzheimer's Disease. Neuropsychology 1995, 9, 313. [CrossRef]

58. Possin, K.L.; Feigenbaum, D.; Rankin, K.P.; Smith, G.E.; Boxer, A.L.; Wood, K.; Hanna, S.M.; Miller, B.L.; Kramer, J.H. Dissociable executive functions in behavioral variant frontotemporal and alzheimer dementias. Neurology 2013, 80, 2180-2185. [CrossRef] [PubMed]

59. Bastin, C.; Salmon, E. Early neuropsychological detection of Alzheimer's Disease. Eur. J. Clin. Nutr. 2014, 68, 1192. [CrossRef] [PubMed]

60. Morganti, F.; Stefanini, S.; Riva, G. From allo-to egocentric spatial ability in early Alzheimer's Disease: A study with virtual reality spatial tasks. Cogn. Neurosci. 2013, 4, 171-180. [CrossRef] [PubMed]

61. Jernigan, T.L.; Archibald, S.L.; Fennema-Notestine, C.; Gamst, A.C.; Stout, J.C.; Bonner, J.; Hesselink, J.R. Effects of age on tissues and regions of the cerebrum and cerebellum. Neurobiol. Aging 2001, 22, 581-594. [CrossRef]

62. Raz, N.; Lindenberger, U.; Rodrigue, K.M.; Kennedy, K.M.; Head, D.; Williamson, A.; Dahle, C.; Gerstorf, D.; Acker, J.D. Regional brain changes in aging healthy adults: General trends, individual differences and modifiers. Cereb. Cortex 2005, 15, 1676-1689. [CrossRef] [PubMed]

63. Park, D.C.; Reuter-Lorenz, P. The adaptive brain: Aging and neurocognitive scaffolding. Annu. Rev. Psychol. 2009, 60, 173. [CrossRef] [PubMed]

64. Nelson, A.J.D.; Powell, A.L.; Holmes, J.D.; Vann, S.D.; Aggleton, J.P. What does spatial alternation tell us about retrosplenial cortex function? Front. Behav. Neurosci. 2015, 9. [CrossRef] [PubMed]

65. Vann, S.D.; Aggleton, J.P.; Maguire, E.A. What does the retrosplenial cortex do? Nat. Rev. Neurosci. 2009, 10, 792-802. [CrossRef] [PubMed] 
66. Dillen, K.N.H.; Jacobs, H.I.L.; Kukolja, J.; von Reutern, B.; Richter, N.; Onur, Ö.A.; Dronse, J.; Langen, K.J.; Fink, G.R. Aberrant functional connectivity differentiates retrosplenial cortex from posterior cingulate cortex in prodromal Alzheimer's Disease. Neurobiol. Aging 2016, 44, 114-126. [CrossRef] [PubMed]

67. Wilson, K.D.; Woldorff, M.G.; Mangun, G.R. Control networks and hemispheric asymmetries in parietal cortex during attentional orienting in different spatial reference frames. Neuroimage 2005, 25, 668-683. [CrossRef] [PubMed]

68. Pouliot, S.; Gagnon, S. Is egocentric space automatically encoded? Acta Psychol. 2005, 118, 193-210. [CrossRef] [PubMed]

69. Lithfous, S.; Dufour, A.; Blanc, F.; Despres, O. Allocentric but not egocentric orientation is impaired during normal aging: An erp study. Neuropsychology 2014, 28, 761-771. [CrossRef] [PubMed]

70. Parkin, A.J.; Walter, B.M.; Hunkin, N.M. Relationships between normal aging, frontal lobe function, and memory for temporal and spatial information. Neuropsychology 1995, 9, 304. [CrossRef]

71. Parsons, T.D.; Carlew, A.R.; Magtoto, J.; Stonecipher, K. The potential of function-led virtual environments for ecologically valid measures of executive function in experimental and clinical neuropsychology. Neuropsychol. Rehabil. 2017, 27,777-807. [CrossRef] [PubMed]

72. Parsons, T.D.; Gaggioli, A.; Riva, G. Virtual reality for research in social neuroscience. Brain Sci. 2017, 7, 42. [CrossRef] [PubMed]

73. Oliveira, J.; Gamito, P.; Rosa, B.; Bértolo, D.; Ribeiro, J.; Sousa, T.; Morais, D.; Ferreira, F.; Lopes, P. Ecologically-Oriented Approach for Cognitive Assessment in the Elderly. In Proceedings of the 4th Workshop on ICTs for Improving Patients Rehabilitation Research Techniques, Lisbon, Portugal, 13-14 October 2016; ACM: New York, NY, USA, 2017; pp. 32-35.

74. García-Betances, R.I.; Arredondo Waldmeyer, M.T.; Fico, G.; Cabrera-Umpiérrez, M.F. A succinct overview of virtual reality technology use in Alzheimer's Disease. Front. Aging Neurosci. 2015, 7, 80. [PubMed]

75. Riva, G.; Baños, R.M.; Botella, C.; Mantovani, F.; Gaggioli, A. Transforming experience: the potential of augmented reality and virtual reality for enhancing personal and clinical change. Front. Psychiatry Front. 2016, 7, 164. [CrossRef] [PubMed]

76. Stevenson, R.J.; Francis, H.M.; Oaten, M.J.; Schilt, R. Hippocampal dependent neuropsychological tests and their relationship to measures of cardiac and self-report interoception. Brain Cognit. 2018, 123, 23-29. [CrossRef] [PubMed]

77. Riva, G.; Serino, S.; Di Lernia, D.; Pavone, E.F.; Dakanalis, A. Embodied medicine: Mens sana in corpore virtuale sano. Front. Hum. Neurosci. 2017, 11, 120. [CrossRef] [PubMed] 